\title{
International students challenges during the COVID-19 pandemic in a university in the United States: A focus group study
}

\author{
Yves Paul Vincent Mbous ${ }^{1} \cdot$ Rowida Mohamed $^{1}$ (D) $\cdot$ Toni Marie Rudisill $^{2}$
}

Accepted: 23 January 2022

This is a U.S. government work and not under copyright protection in the U.S.; foreign copyright protection may apply 2022

\begin{abstract}
Research suggests that the COVID-19 pandemic has deeply impacted college students. However, very few studies have attended to the specific plight of international students. The purpose of this study was to document challenges international students may have encountered while studying in the United States during the pandemic. Focus groups $(\mathrm{N}=4 ; 13$ students total) were conducted with students who were $\geq 18$ years of age, enrolled at least part-time, on an F1 visa, and non-resident alien, who did not have parents/guardians living in the United States and were able to read and write in English. Focus groups lasted $1.5-2 \mathrm{~h}$ in duration and followed a standardized script. These sessions were audio-recorded and professionally transcribed. Two researchers performed qualitative content analysis. Six themes emerged from the analysis and included residency challenges, lifestyle changes, coping, negative affect, social support, and university structure. It appears that the challenges associated with residency and lifestyle directly impacted students' negative affect. However, the remaining themes moderated this relationship. These findings highlight the role universities can play in providing relief to international students during these challenging times and suggest areas for improving their experiences.
\end{abstract}

Keywords COVID-19 Pandemic $\cdot$ International students $\cdot$ Higher educational institutions $\cdot$ Qualitative research $\cdot$ Focus groups

\section{Background}

The COVID-19 pandemic has exacerbated college students' mental health risk factors and other health concerns jeopardizing students' academic success. International students, in particular, may have incurred additional burdens stemming from their vulnerability due to many unique challenges

Yves Paul Vincent Mbous and Rowida Mohamed have equal contribution.

Rowida Mohamed

rmm0055@mix.wvu.edu

Yves Paul Vincent Mbous ypm0001@mix.wvu.edu

Toni Marie Rudisill trudisill@hsc.wvu.edu

1 School of Pharmacy, Department of Pharmaceutical Systems and Policy, Robert C. Byrd Health Sciences Center, West Virginia University, P.O. Box 9510, Morgantown, WV, USA

2 School of Public Health, Department of Epidemiology \& Biostatistics, Robert C. Byrd Health Sciences Center, West Virginia University, Morgantown, WV 26506-9190, USA pertaining to living abroad, adjusting to the host country's culture and norms, language barriers, visa policies, discrimination, prejudice, and being away from essential social support systems, such as family and friends (Essau \& Trommsdorff, 2016; Heng, 2018; Poyrazli \& Lopez, 2007; Smith \& Khawaja, 2011; Taliaferro et al., 2018; Zhai et al., 2021). Compared to 2019, the prevalence of major depressive disorder and generalized anxiety disorder were 2 times and 1.5 times higher, respectively, among international students during the pandemic (Chirikov et al., 2020).

Prior to the pandemic, anxiety and depression were already elevated among internationals students (Alharbi \& Smith, 2018) with reports from the literature finding high levels of depressive and anxiety symptoms, $45.3 \%$ and $24.7 \%$, respectively among this subpopulation. In Australia, a mixed-method study using the Depression Anxiety Stress Scale reported that local students displayed "normal" to "mild" levels of depression and anxiety, whereas Chinese students reported significantly higher levels (Redfern, 2016). Similarly, in the United States (U.S.), international students reported higher levels of stress compared to European or students with U.S. residencies (Fritz et al., 2008). A 
recent work found that the prevalence of depression among international students, which ranged from $22.6 \%$ to $45.3 \%$, was higher than local students and even the general population (Saravanan \& Subhashini, 2021; Wang et al., 2020). Accountable factors for such disparities included English incompetence, acculturative stress, social belonging, and perceived discrimination (Brunsting et al., 2018; Shadowen et al., 2019). Thus, this population warrants further examination, especially during these unparalleled times induced by COVID-19. Pandemic-related border closings, drastic visa, and immigration policy changes in the U.S., such as the deportation of international students taking online courses, all increased the psychological burden on international students (Chirikov \& Soria, 2020; Meiksin, 2020; Redden, 2020).

Despite their unique and complicated challenges (Chen et al., 2020), prior studies have often conflated international students' needs with those of domestic students, and few studies have attempted to describe the challenges faced by international students living in the U.S. during the ongoing pandemic. Marbang et al. (2020) focused chiefly on immigration regulations and policies regarding F-1visa for international students (Marbang et al., 2020). Another study examined international students' transition from faceto-face to virtual learning during the COVID-19 (Trout \& Alsandor, 2020). Some studies only included international students from specific countries. For example, one study focused on Vietnamese students only (Ngoc Cindy Pham \& Juehui Richard Shi, 2020). Thus, despite the high number of international students in the US and their contributions to the US educational system, their experiences and challenges remain understudied (Alharbi \& Smith, 2018). Therefore, examining international students' general challenges during this critical time is crucial to provide adequate and prompt student protection measures and support. This study aims to depict common challenges among international students from diverse countries studying at a public university in the U.S. during the COVID-19 pandemic. This work will procure much-needed depth on the extant awareness of international students' psychological and behavioral aspects during COVID-19.

\section{Methodology}

\section{Study Design and Population}

Four focus group sessions were conducted with a total of 13 participants; all enrolled at West Virginia University (WVU), West Virginia, U.S. Focus groups are more useful and less expensive than individual interviews for revealing a wide range of participants' beliefs and experiences through a moderated interaction (Morgan, 1996). The sample size was defined by data saturation-i.e., at the point where no new themes from participants emerged. The inclusion criteria were as follows: (1) students must be enrolled at least part-time at West Virginia University, (2) be 18 years of age or older, (3) be an international student on an F1 visa, and non-resident alien, (4) have parents/guardians that do not live in the U.S., and (5) able to read and write in English. No prior relationship existed between the study authors and participants.

\section{Procedure}

This study was approved by the WVU institutional review board. Participants were recruited through on-campus advertisements, WVU listserv, Facebook, and flyers at grocery stores via convenience sampling. International students who were interested in taking part in the study sent an email to the principal investigator (TR) asking for participation. Upon this first contact, students received a consent letter detailing the study purpose. Focus groups were conducted from December 2020 to January 2021. Due to the pandemic, focus groups were conducted using Zoom conferencing technology. Nobody attended the focus group other than the participants and the moderators, and no recruited participants dropped from the study at any point during the focus group sessions. Focus group size ranged from 2 to 5 participants (Jayasekara, 2012). Moderators (YPM \& RM), trained by an experienced researcher (TR) with qualitative and quantitative research experience, employed a standardized semistructured interview guide. The interview guide was created based on preliminary information collected from a review of published literature and experts' opinions (Chirikov \& Soria, 2020; Laws \& Ammigan, 2020). The interview guide (Supplementary Table 1) was pilot tested with one group of two international graduate students. One moderator (YPM) led all the focus groups to minimize interviewer bias.

Each focus group began with introductions, an explanation of the study, and informed consent procedures. Throughout the sessions, prompts were used to increase the depth of engagement and acquire complete answers. Each focus group was audiotaped and lasted between 1.5 to $2 \mathrm{~h}$, with an average focus group time of $1.75 \mathrm{~h}$. The audio recordings were transcribed verbatim by a professional transcription service and reviewed by YPM and RM for accuracy. A summary of the focus group conversation was emailed to participants within three days for comment to ensure the validity of provided answers. The researchers also used the summaries to determine when data saturation occurred. No areas of dissonance were identified. The COnsolidated criteria for REporting Qualitative research (COREQ) were followed throughout the study (Supplementary Table 2) (Tong 
et al., 2007). Across the results, the participants views are presented in italics.

\section{Data Analysis}

Using qualitative content analysis (Glaser \& Strauss, 2017), three members (TR, YPM, and RM) of the study team thoroughly and repeatedly reviewed the transcripts. Working independently, each developed a set of codes for qualitative data derived from each question and each group. Codes were condensed into mutually exclusive and substantive categories. YPM and RM consolidated the codes into themes, which TR validated against the transcripts to ensure appropriateness. Conflicting opinions on the contents of a theme were discussed and resolved by the research group. Cohen's Kappa $(k)$ was employed to measure the level of agreement between the coders, and the interrater/intercoder agreement (Kappa) score was $84.94 \%$ (Mchugh, 2012). Quotes that represented the theme or sub-theme were labeled according to the focus group they attended. For example, the first focus group is labeled FG1, and the second focus group FG2. Demographic characteristics were summarized via descriptive statistics using SAS Version 9.4. NVivo software v.12 was used to manage and code the data.

\section{Results}

Table 1 provides the demographic characteristics of study participants $(\mathrm{N}=13)$. Six themes emerged from this study, namely, (1) residency challenges, (2) lifestyle changes, (3) negative affect, (4) university structure, (5) coping, and (6) social support. Table 2 details the main themes, codes, and frequency in the transcribed text. Figure 1 shows the relationship between these themes upon which the upcoming discrete descriptions were based. It appears that residency challenges and lifestyle issues drove the feelings of negative affect during the pandemic. However, this relationship was influenced by the university structure in place, coping mechanisms, and social support. As international students often compared their experiences to American students, the latter will henceforth be referred to as "native" or "local" students.

\section{Residency Challenges}

Salient residency challenges encountered by international students fell within the following categories: acculturation, bureaucracy and administrative hurdles, discrimination, visa policies, traveling restrictions, job search, and political climate. Culture shock is one of the most commonly reported
Table 1 Demographic characteristics of participants

\begin{tabular}{|c|c|c|c|c|}
\hline Characteristic & Mean & SD & $\mathrm{N}$ & Percent \\
\hline Age (in years) & 26.3 & 3.8 & & \\
\hline \multicolumn{5}{|l|}{ Sex } \\
\hline Male & & & 4 & 33.3 \\
\hline Female & & & 8 & 66.7 \\
\hline Missing & & & 1 & \\
\hline \multicolumn{5}{|l|}{ Race } \\
\hline White & & & 4 & 33.3 \\
\hline Black & & & 2 & 16.7 \\
\hline Asian & & & 5 & 41.7 \\
\hline Other & & & 1 & 8.3 \\
\hline Missing & & & 1 & \\
\hline \multicolumn{5}{|l|}{ *Continent } \\
\hline Africa & & & 2 & 16.7 \\
\hline Asia & & & 7 & 58.3 \\
\hline Australia & & & 1 & 8.3 \\
\hline Europe & & & 1 & 8.3 \\
\hline South America & & & 1 & 8.3 \\
\hline Missing & & & 1 & \\
\hline \multicolumn{5}{|l|}{ Graduate student } \\
\hline Yes & & & 11 & 84.6 \\
\hline No & & & 2 & 15.4 \\
\hline
\end{tabular}

Abbreviations: $\mathrm{SD}=$ standard deviation

Percentages may not add up to $100 \%$ due to rounding. * Representative countries from the listed continents- Africa: Nigeria; Asia: China, India, Malaysia. For the purposes of anonymity, only countries from continents with more than 1 participant were listed

challenges experienced by non-immigrant students studying in the U.S. Issues with language, communication, cultural perspectives often dampened the initial contact between international students and their local peers, and this often translates into the way research is conducted, peer appreciation and of course attitudes:

"The general approach to learning and education and collaboration here is if you are more extroverted.... you have an advantage...... There is a preference for those kinds of people. Sometimes I felt that I am not able to speak my mind, I am not able to be authentic." (FG2)

Further, with COVID-19 and distanciation measures, newly admitted international students freshly adapting to their new circumstances experienced a rude awakening:

"The culture differences were starting to get to me, so I was not able to communicate with anybody. I was not able to make friends....in my second semester .... When this pandemic started, I was having these panic attacks, and I was feeling isolated, secluded." (FG2) 
Table 2 Coded themes and subthemes

\begin{tabular}{|c|c|c|}
\hline Theme & Subthemes & Frequency \\
\hline \multicolumn{3}{|c|}{ Residency challenges } \\
\hline & Acculturation, social isolation & 10 \\
\hline & Bureaucracy, administrative and unnecessary hurdles & 11 \\
\hline & Discrimination & 16 \\
\hline & Diversity & 5 \\
\hline & Job search & 13 \\
\hline & Political climate & 21 \\
\hline & Traveling restrictions & 18 \\
\hline & Visa policies & 20 \\
\hline \multicolumn{3}{|c|}{ Lifestyle } \\
\hline & Change in the work environment & 37 \\
\hline & Pandemic-induced attitudes & 11 \\
\hline & Work-life balance & 28 \\
\hline \multicolumn{3}{|c|}{ Negative affect } \\
\hline & Concern for relatives & 14 \\
\hline & Homesickness & 12 \\
\hline & Loneliness & 18 \\
\hline & Loss of motivation, focus, and productivity & 20 \\
\hline & Mental health, worry, fear, stress, anxiety, negative emotions & 62 \\
\hline & Relationship dynamics & 12 \\
\hline & Sense of belonging & 11 \\
\hline & Uncertainty & 28 \\
\hline Coping & & 25 \\
\hline \multicolumn{3}{|c|}{ Social support } \\
\hline & Family \& Friends & 50 \\
\hline & University & 35 \\
\hline \multicolumn{3}{|c|}{ University structure } \\
\hline & Action, directives, and structural guidance & 15 \\
\hline & Centralization of authority at the department or advisory level & 5 \\
\hline & Financial support (for special populations also) & 11 \\
\hline & Flexibility or rigidity of programs & 10 \\
\hline & Graduation and research delays & 18 \\
\hline & Output requirement & 13 \\
\hline & Paradigm for research and teaching & 18 \\
\hline & Relationship with faculty & 23 \\
\hline
\end{tabular}

Fig. 1 Relationship between major themes

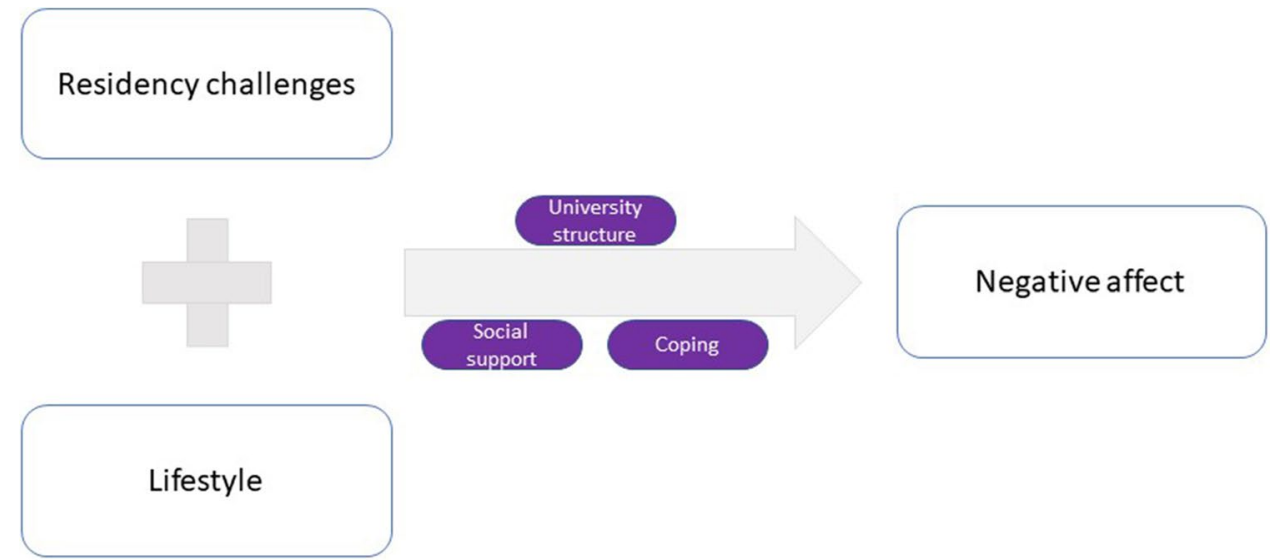


Acculturation was exacerbated by a perceived demarcation between international and native students in what the former referred to as innumerable and unnecessary hurdles at the administrative levels:

"...Having to deal with the bureaucracy in America sometimes is so annoying, and just all the loopholes and just like the incoherent responses that you'll get from different offices. And just no one can ever give you like a straight answer.........we are still expected to do everything that our fellow colleagues (native students) are doing...... but then we have all these things going on, administration-wise.... it's just tiring for me." (FG2)

On the $6^{\text {th }}$ of July 2020, the U.S. Immigration and Customs Enforcement (ICE) agency announced temporary exemptions for non-immigrants students taking online classes in the Fall of 2020. These exemptions chiefly precluded non-immigrant F-1 and M-1 students currently attending schools operating entirely online from taking a full online course load and remaining within the United States territories. Further, exemptions prohibited visa obtention for overseas students enrolled in fully online programs. Granted, these exemptions were partially rescinded no less than two weeks after their announcement; however, at the time, it put tremendous stress on international students' shoulders:

"When.... they were going to revoke our visas if we only had online classes, I literally could not work for like the two days after that happened, because I was just stressed, and I could not get my mind off it." (FG1)

Unfortunately, for some students awaiting to enter the U.S., the partial lifting of these restrictions did not accelerate the procurement of visas, as in some countries, embassies were either closed or functioning at a reduced capacity.

The pandemic enforced a shutdown that translated into traveling restrictions precluding international students from taking annual vacations to their respective homes and rekindling with families and relatives. As a result, international students felt confined within the U.S., a feeling further exacerbated by the freedom enjoyed by their local counterparts:

"I would say that definitely, they (local students) are more privileged...because they had the option of going home if they wanted to, even maybe for a weekend ....... I see that as a luxury for me." (FG2)

While remaining in the country, non-immigrant students had very limited choices with respect to job search for both newly graduated and current students. The high rate of furlough throughout the pandemic made hiring locals a priority. As one student described:
"I had a lot of connections through my Ph.D. that were going to help me in the current moment, but they cannot help because of the COVID. They just say I cannot hire anybody from outside of the U.S. because of the COVID; we are prioritizing Americans." (FG3)

The residing political climate aggravated all these challenges. In the midst of a presidential election and a country polarized over numerous issues, international students were flooded with dire news about global health, safety, morbidity, and mortality from COVID-19, activism, and racial issues (George Floyd, Black Lives Matter, discrimination, etc..) (Eichstaedt et al., 2021; Franz et al., 2021; Ho, 2021; Toure et al., 2021). Restricted in their movements and leisure activities, the presiding climate became even more pressing than usual for international students confined to their homes and having for sole source of communication with the outside world, the information disseminated by news channels or social media. For some, especially those of Asian origin, discrimination fueled by the politicians could be felt in their daily interactions, spurred on by labeling the COVID-19 the "Chinese virus":

"I had a roommate.... And like, in my case, I am not American, but I am a White male. So, if I do not speak, I think I pass, but she is Asian. So, as the beginning of the pandemic, it was really bad for her because people would just like walk away from her or say things in public because they thought she was from China and that she had the virus." (FG3)

\section{Lifestyle}

Under this theme, the most recurring sub-themes pertaining to the ongoing COVID-19 pandemic were changes in the work environment, work-life balance, and attitudes. Lecture modes were entirely made virtual. This shift meant that important readjustments to new learning environments had to be made. Some students were stuck overseas due to visa policies and had to adjust to time differences and logistic issues to assist lectures. For most, their home became their office/lab space; thus, the physical and cognitive separation of work and home spaces vanished. There was an outcry from the failure to accommodate for such a shift:

"I think they (the University) need to adjust to meet the needs (of students) in terms of the pandemic and in terms of academics, honestly.... I think we need to reduce the amount of Zoom hours..... I think students should be spending less time (on computers) ... and we still have to look at our computers again to do.... research and data analysis. And then we are also looking at a computer for three hours (for any given lecture)." (FG2) 
On top of the burden of screen time, students also briefly mentioned that because they had to stay at home more than usual, this led to a higher than usual consumption of utilities, and financial support to that end was not available for international students. Concomitantly, the preexisting work-life balance was upended. Students, even those with jobs, were accustomed to spending the day at work or studying and enjoying the evening with friends or partaking in various extracurricular activities (dance, gym, local outings, social events). With the pandemic, invitations to social events had to be canceled, and close relationships progressively grew sour as a result. For others, not being able to go to cafés to study or restaurants /pubs with friends after work left them with nothing but work or studying to do during their leisure time. Disrupting this balance added to their woes.

Relationships were not only impacted as a result of cancellation or refusal to engage in social events but also as a consequence of the perceived levity towards the adoption of social distanciation measures. For international students, even those with assistantships or bursaries, the cost of living was already fairly high, and thus, complaints regarding costs of amenities (food, groceries, gas, electricity, water, trash services, etc.), but most importantly, costs of healthcare were rife. International students already feared the high costs associated with medical visits (ER, dental, etc.). During the times of a global pandemic, this became an even pressing concern, such that any perceived lax behavior from one's entourage was cause enough for additional stress/ worry and/or relationship frost.

\section{Negative Affect}

Negative affect was driven by concern for relatives, homesickness, loneliness, loss of motivation, focus and productivity, mental health (worry, fear, stress, anxiety), relationship dynamics, sense of belonging, and uncertainty. Traveling restrictions certainly brought international students a certain degree of relief stemming from not running the risk of contaminating family and relatives had they traveled back to their home countries. However, that was a double-edged sword, as such concerns precluded the purchase of flight tickets from providing them with much needed familiar closure:

"I also had another peak of desperation at the beginning of December (2020) and, um, I was almost on the verge of getting air tickets again, but I realized that.... I could be carrying the infection back to my home where I have my grandma, parents and all that. So, I was going crazy. I was just losing my sanity here.” (FG2)

Further, some non-immigrant students feared burdening their families with concerns about their own health. As international students ran the risk of contracting COVID-19 as a result of what they perceived as circumstantial respect of distanciation measures among the general U.S. populace, they often wondered how their relatives would react should they get infected or, worse, pass away while in the U.S.:

"I am afraid that I will get the COVID and that I will like end up in the hospital. So, I feel like it will be really bad for my family because they are not here. I will have to pay a lot. ... I am afraid because.... if I get it and if I die here, like it's the worst nightmare for my family and for my parents." (FG3)

Another student remarked:

"One of the fears that I had when everything started was if I died here, I am just dead here. I do not know if my family will know since I live alone. So, if I died in my apartment, like I am gone, no one is going to know for weeks, maybe months that I died." (FG4)

The next salient source of negative affect was homesickness. Unable to travel to their home countries and to be cut off physically from relatives and friends, international students' sentiment of homesickness was further accentuated by the uncertainty concerning returning to the U.S. should they choose to travel. There was uncertainty about being able to fly out and being allowed to return, especially at the height of the crisis; this coupled with a perception of "privilege" and freedom that their local counterparts enjoyed seemed to aggravate their plight.

As restrictions and isolation compounded during COVID19, so too did loneliness. Discontinuation of social gatherings implied alternative methods, which were often solitary for singles:

"You find yourself drinking alone because you can't have those social gatherings. And so, you just going to have to go get your beer at Kroger and drink alone."

(FG1)

Relationship dynamics were one of the causes of negative affect. Unable to partake in social events and forever rescinding invitations by friends further reduced international students' social circle. This became a source of friction as people accepted the pandemic at a different pace. Very few options were left to international students as Zoom-based social activities were not ubiquitous:

"My friends definitely stopped...... inviting me because all I would say is, no, I am not showing up. I would make up reasons. I would come up with excuses not to go out......it definitely affected some of my friendships." (FG1)

Some friendships were irretrievably broken because of the laxity exhibited with respect to distanciation measures, 
as this became a source of a feud that could no longer be dismissed. Pandemic enforced distanciation and changes in social relationship dynamics meant that international students were suddenly in want of human interactions. Some resorted to dating apps; others tried to rekindle past relationships with former acquaintances or spent more time than usual communicating with their overseas relatives. The typical warmth of collegial office conversations was also lost, just as well as the ubiquitous "live" help from colleagues upon encountering an issue at work, in their studies, or research. Everything had to happen via electronic communications where the human touch was lost. In the words of one international student:

"I think it had a really high impact on my mental health. I felt even more isolated. The only places where I had this sense of belonging to the group .... was in research. I would just go there and do research in the research room with the other graduate students where I could talk.... with the COVID, I just stay at home, and I cannot like do activities with other people anymore. So, it was really harsh on me." (FG3)

The shift in the working environment and education paradigm engendered in some a loss of motivation, focus, and productivity. International students credit the online aspect of their work as a chief factor in their loss of productivity. The delineation between home and office space no longer existed:

"I wake up and take my breakfast, and then I go directly to class...I don't have like this time where I am like that's like the limit; this is my home; this is my class. It's like all mixed together...it definitely does not help you to focus in class" (FG3)

Taking classes online for some was simply not as enriching as the live experience, and this reflected in their grades as the pressure of exams and work went unrelenting. Graduate students' reliance on software supplied by the university inferred dealing with looped ambiguous emails, IT issues, remote access to shared drives, software crashes, network, and internet connections, scheduling of time in the office to access these resources (distanciation measures), which participated to their loss of efficiency. For international students living as couples and having families, dealing with young children at home (closure of daycare centers) while attempting to focus in class was not deemed the easiest of jobs.

The detrimental effect resulting from all the aforementioned predisposition factors was the impact on mental health. This particular code, encompassing mental health, worry, fear, stress, anxiety, and negative emotions, as shown in Table 2, grossed the highest number of references $(n=62)$. For most international students, the safety and well-being of relatives was a trigger for mental health issues-mainly anxiety and stress. Stress also increased as working hours got longer, and no dissociation existed between the office and physical home spaces:

Being "in one place" meant becoming attune to things that one would not have usually paid attention to were they to embrace their usual routine, namely matters related to the political climate, death tolls, wars, risk of expulsion (visa policies), issues of discrimination. Attitudes and financial matters were at the heart of international students' mental issues. Some students who were unable to remain productive were given the ultimatum to either pursue their work or see their assistantship rescinded:

"One thing is you get paid for what you do and if you are not doing it, you don't get paid. .... So, I was really struggling in July because I wanted to go home. I had told my advisor that I would not be able to work...... and she was expecting me to go to the lab. I said, I don't feel safe enough to go on and work...... You can give me some other job... and she said, okay, if you're not working, then I have to pay someone else to do that job. And I cannot keep you on the payroll. I mean, I did not get paid for like four month and a half......it was, it was kind of stressful for me." (FG2)

Feeling disconnected culturally, being discriminated against, and facing the prevailing sociopolitical climate that made them feel unwanted, reinforced a sense of remoteness:

"The discrimination has definitely decreased my sense of belonging here. Just like seeing what people say and what they genuinely think with so much hate, that makes me feel not welcomed here, and it has definitely impacted my mental health.” (FG2)

Another student added:

"I think in my case it had very negative impact with respect to the feeling of belonging.... I feel now that as internationals, we are the first ones to be dismissed and not to be considered because the priority is the American people." (FG3)

All these woes accentuated uncertainty in the minds of non-immigrant students. These issues tied chiefly to job uncertainty as a result of perceived preferential criteria, graduation delays as a shift in work environment, which meant postponing experiments or internships necessary for curriculums, traveling uncertainty as one could not return to the U.S. following an international trip because of current visa policies, financial insecurity from assistantships, and in general a deep-rooted malaise, no doubt sprung in part from perceived preferential treatment, that instilled a lugubrious perspective for what the future might hold. 


\section{University Structure}

As previously asserted, several factors moderated the effects of lifestyle and residency challenges upon negative affect. One such factor was the university structure as it branched into education system features (encompassing graduation and research delays, flexibility or rigidity of programs, relationship with lecturers, or output requirement) and structural governance concerned with or lack thereof action, directives and structural guidance, and centralization of authority. At the beginning of the pandemic, laboratories were shut down, recruitment of participants for research paused, research got postponed, and graduation dates were pushed due to a shift in teaching paradigm (shift from live to online delivery).

The flexibility or rigidity of established curriculum refers to the fact that some students could choose when to take certain courses but not which courses to take; for some, this was tied to the contracts stipulated in their assistantship, and for others, given the scarcity of funds, they could not afford to take up a course they deemed interesting. The fact that this was not the case, as perceived, for local students increased the sense of not belonging. Faced with the inability to take classes of their choosing and having to deal with upended work conditions, relationships with faculty became crucial. For some, prized advisor-mentee relationships became an additional source of stress:

"My relationship with my advisor definitely stressed me out a lot. I was mostly focusing on how to please her or how to impress her. And I sidelined my academics. I completely forgot that I have.... courses, that I need to study, to perform...." (FG1)

For those with better mentor-mentee relationships, there was still an unbridgeable gap, perhaps owing to acculturation and students' expectations:

"Although I know that they do care for me, I'm not really sure if I am in... some sort of trouble, whether I would really get their help or not. Because I have faced some issues because I was going through some cultural shocks.....and they did tell me that you can get help in the Carruth center.... But that's like, if I need some help, I have to go to some other person and seek help there? I am not really sure if I will be able to communicate my problems with my advisor.... and if I really do that, I am not sure whether I will be in a safe place." (FG2)

With respect to lecturers, most international students were grateful for the flexibility exhibited by professors in terms of leniency for grades and accommodating schedules for private meetings. However, despite the ongoing pandemic, the output requirements remained the same. International students expected the university/departments to consider the potential negative effect engendered by pandemic and to help readjust certain academic expectations or requirements.

International students were equally concerned with the lack of action, directives and structural guidance, and centralization of authority. While being afraid for their health, some international students appreciated the response of their departments and university (Global Affairs Office) through active communication and engagement to maintain safe spaces:

"During the lockdown, when the things were locked down, our department kept in constant communication. They were in constant communication with us. And if anytime I had any query people were very supportive there. And also, right now, our lab is open, and we can go, but it never felt to me, like I am putting my life at risk." (FG1)

Nevertheless, some conversations were deemed unnecessary, especially those pertaining to employment status and assistantships. According to international students, some professors were understanding and cognizant of the difficult times. However, others remained completely oblivious of how the situation could have affected their students. International students expected some directives at the University level enforcing some regulations pertaining to the level of expectations:

"I would like to not have unnecessary conversations on my employment status.... so just maybe, maybe on an institutional level, the university should talk about, you know, assistantships. Because at this point, the experiences that people have, depending on who your instructors or bosses are, some are lenient because of the pandemic, some are completely like oblivious of the pandemic and expectations. So, I feel the university could just issue out like something to all instructors who are having research or teaching assistants to manage their expectations and to be cognizant of the fact that we are in a pandemic." (FG2)

The lack of directive and perceived misalignment of priorities at the departmental level was further compounded by what non-immigrant students termed a lack of structure. This referring to the lack of a distinct structure, aside from what was offered departmentally, set to address their grievances:

"I feel like in academia, we depend a lot on the positions of our advisors in our department. And it's like, they have a lot of power, and there is no like human resources. There is no structure to tell you like what to do if it should be one way or another one." (FG3)

Having to depend on a restricted nexus of individuals to lodge any complaints when the concerned behave in a 
business-like fashion ("you are being paid to do your project") and often appear uninterested adds to a feeling of uncertainty and powerlessness in the face of inequitable centralization of authority.

Opinions concerning the impact of departmental financial support were, for the most, auspicious. Those who received it were relieved not to have another source of worry, all the more so for those whose families depended on this support:

"The only reason I am able to do a Ph.D. as a mother is because there is a research assistant position, which allows me to at least...... meet my needs until I finish my school and my education. And so that is a very big deal." (FG2)

\section{Social Support}

The mitigating effects of social support in our purported explanatory relationship stemmed from the assistance or lack thereof from family, friends, and department and/or university. Relatives and friends played a substantial role in helping students manage the negative effects of residency and lifestyle hurdles, mostly of recomfort and monetary nature, brought about by the pandemic. Not being able to see their family had the converse effect at two levels: first, the incessant worry about their well-being, and second, lacking (comparatively to locals) that intimacy had their families or relatives been close by:

"It's really hard for international students to stay in this state at this time. And there is like, no emotional support because you are by yourself, all your friends or your family are in another country, or they could be in another state. And the only thing that you have to do is fight to live another day." (FG4)

At the university level, the discourse splits into the support received from the International Office or Global Affairs Office and at the departmental level. There is an expected duality among responses. Some international students appreciated the open communication regarding ICE regulations which conveyed the university's willingness to address the problem and provide some form of temporary relief. Others felt that social support from the International Office was sorely lacking, especially when there was no attempt to organize social events in any form pertaining specifically to international students, actively engaging them in any form of dialogue to identify what was needed and what they could do to improve their respective situations.

At the departmental level, conflicts with advisors, "cold" referrals to university-based counseling centers, perceived lack of empathy all seemingly had a common starting point, namely, the lack of communication addressing student grievances, such as those related to ICE stipulations:

"And that for me felt kind of like a knife in the back, you know, like it felt like I am bringing so much for the department and my department must be maybe $75 \%$ international students and we bring publications to them ...... They didn't even bother to send even one email to explain the situation. And what was their plan of attack to protect us? And it just felt like we had no support. We had to go through that by ourselves......... it was so much stress." (FG4)

These reactions were mixed as, for some students, advisors and department lecturers stepped up during this ordeal.

\section{Coping}

The last mitigating factors to be addressed are coping methods used by non-immigrant students to reduce the negative effect imparted by residency and lifestyle challenges. The closing of amenities and recreation centers took away international students' diversion tools. Some recreated gym spaces at home through various approaches. Others, feeling the brunt of restriction and isolation turned, as mentioned previously, resorted to drinking alone, counseling services, the adoption of pets to alleviate mental issues, or zoom services for digital social gatherings:

"Because of the COVID and being home a lot, I got a pet, a cat, I adopted her. So that has been very therapeutic... I found a different way to connect with my friends. Now we do it on zoom. So, like I will just open my zoom, and then we kind of just do our own things." (FG2)

Eating has been used as a way to cope in two contrasting ways. Some took up emotional eating as a form of coping, while others became more conscious of their diet and sought to amend it to improve their mental health. Finally, a select few adopted new habits, including painting, reading, or learning about fashion design:

"On the positive side, I learned new things as I have been reading a lot. Before, I couldn't even complete a book, and now, I have read several books, and I am getting better at it. So, I am really proud." (FG3)

Another student remarked:

"I have started painting. So, I painted several things in like watercolors, and it was really good for me for my mental health." (FG3) 


\section{Discussion}

This study focused on international students' experiences during the COVID-19 pandemic and explored the challenges they faced as well as the impact on their well-being. The findings, which centered around six themes, suggested that the pandemic put international students in a more precarious position, potentially exacerbating preexisting challenges. Challenges reported by our participants were similar to both domestic students and international students worldwide. However, unique challenges of international students living in the U.S. during COVID-19 were also identified.

In this study, international students listed challenges similar to those reported by domestic students in the literature, including stress related to the online teaching paradigm, delayed graduation concerns, worry about self and family health, uncertainties of future employment, change in the studying/working environment, and social isolation (Xiaomei et al., 2020). Lessons from this pandemic are crucial, as global health and safety remain uncertain in the face of the highly mutable SARS-CoV-2 virus. International students contribute enormously to university economies and research programs. According to the Association of International Educators, international students studying at U.S. colleges and universities contributed $\$ 41$ billion to the U.S. economy during the 2018-2019 academic year (Higher Education Fourth Supplemental Letter. American Council on Education, 2020). It has been estimated that a potential drop in international enrollment could cost schools $\$ 23$ billion during the pandemic (Higher Education Fourth Supplemental Letter. American Council on Education, 2020). Attending to international students' perceived issues could help design preventive countermeasures to promote international students' well-being and maintain revenues for the hosting universities.

Parallel to international students worldwide, participants in this study reported that having a limited social circle, not being able to go back home, and homesickness affected their well-being (Gupta \& Agrawal, 2021; Pappa et al., 2020; Trout \& Alsandor, 2020). Lack of social connection plays a vital role in shaping international students' well-being (Thi Tran, 2020). Thus, it is crucial to foster international student connectedness during the pandemic and afterward. Universities could improve relations between domestic and international students through domestic-international student friendship programs (International Student Services - Columbus State University, 2021). These programs have the potential of helping international students adjust to living in a new culture, expand their social circle, and enhance their sense of belonging (Glass \& Westmont, 2014).

Similar to the literature, our participants described a climate of microaggression and overt discrimination toward international students, specifically those of Asian origin (Ngoc Cindy Pham \& Juehui Richard Shi, 2020). The biased framing of COVID-19 as a "Chinese virus" by the media and politicians negatively impacted the experiences and well-being of international Chinese students in the U.S. (Zheng et al., 2020). Given the increased perceived discrimination, universities should ensure that international students are aware of bias-related incident/discrimination reporting systems on and off-campus. It has been suggested that cross-cultural friendships and community engagement could potentially reduce bias and discrimination (Kwenani $\& \mathrm{Yu}, 2018)$. Thus, hosting universities could also engage international students in community activities.

Additionally, international students were dissatisfied with the International Students' Office (ISO), mostly pertaining to their communication with respect to ICE regulations, legal status, orientation, and guidance for administrative paperwork (in-and-out of campus), and commitment to social blossoming during the pandemic. Previous studies had emphasized the perceived lack of support and guidance from ISO regarding tax and immigration matters, clarity of administrative information, and planning for international students' dedicated social activities, pre-pandemic (D. Chen \& Yang, 2014; Heng, 2017). Universities, in cooperation with ISO, could establish an open forum to encourage international students to openly voice their concerns, similar to what has been initiated at the University of Wisconsin-Madison, where an open forum was created to facilitate discussions on racial tensions in the U.S.( International Student Services - University of Wisconsin-Madison, 2020). Moreover, the legal status of international status should be reviewed and perhaps extended to account for deviations and delays created by the pandemic. In that line, the Canadian government has extended its Post-Graduation Work Permit (PGWP), the equivalent of the U.S. optional practical training (OPT), by 18 months to provide relief and support as well as a better chance to find jobs after graduation (Immigration, Refugees and Citizenship Canada, 2021).

However, our study highlighted some unique themes induced by the pandemic that were not reported in the literature before COVID. For example, prioritizing domestic students over international students in the job market which made it much more complicated and stressful for international students to find a job opportunity in the U.S (Job search theme), uncertainty of being able to go back home due to the pandemic lockdown, travel restrictions, change in working environments through remote working and learning and its associated "loss of productivity during the pandemic", graduation and research delays due to labs shutdown and patient recruitment cessation, concerns for friends and family getting infected with COVID-19, discrimination of Asian students and stigmatizing them for being the reason of the current pandemic. Additionally, we have found that 
although some challenges have been reported in the literature before the pandemic, the dynamics are entirely different. For example, after the pandemic started, obtaining an H1-B visa, the visa used by employers to hire international students, has become much more complex and costly for both employers and employees. Also, in the context of lack of social support, despite having been well-documented prior to COVID, the extra level of support required during the pandemic combined with lack of ability to go back home due to newly enacted visa rules or having to have a complete in-person class, canceled flights, and global lockdown, highlights how these aspects pre-COVID were either unprecedented or exacerbated during the pandemic. This puts emphasis on the necessity of conducting more research to quantify the impact of these changes on international students' mental health.

\section{Limitations}

While this study's findings add to the extant literature, they are not without limitation. The study was limited by its small sample size and convenience sampling technique. The COVID-19 pandemic is an evolving crisis, and this research only focused on a particular period of time. In addition, we enlisted only international students living in rural Appalachia, thereby limiting the findings' generalizability. Further, some of these findings may not be limited to international students but could also extend to native students. Despite these limitations, our study is the first to address the challenges encountered by international students from diverse countries studying in the U.S. during the pandemic from a broader perspective. So, we were able to capture a comprehensive set of themes that have not been reported before in the literature during the pandemic. Also, we portrayed how such challenges differed from one student to another in the context of their personalities, coping mechanisms, and support systems available to them, which is consistent with previous literature (Almomani et al., 2021; Hu et al., 2020). Finally, this study provides practical and feasible directions towards building a support structure by hosting universities to their international communities.

\section{Conclusion}

The pandemic has highlighted international students' vulnerabilities and their challenges. The main facet the themes jointly highlight is international students' need for more support from the hosting university. University support could help mitigate the anxiety experienced by international students during the pandemic. Universities should actively cultivate friendlier relationships between staff, international students, and domestic students and proactively attend to international students' needs to respond quickly during a crisis.

Supplementary Information The online version contains supplementary material available at https://doi.org/10.1007/s12144-022-02776-x.

Author Contributions Conceptualization and design: Rowida Mohamed \& Toni Marie Rudisill. Drafting of the manuscript: All authors. Critical revision of the manuscript for important intellectual content: All authors. Thematic analysis: All authors. Study supervision: Toni Marie Rudisill.

Data Availability Transcriptions are kept by the authors. Interested researchers can access them by contacting the corresponding author.

\section{Declarations}

Conflict of Interest Statement No conflict of interest has been declared by the author(s).

\section{References}

Alharbi, E. S., \& Smith, A. P. (2018). Review of the Literature on Stress and Wellbeing of International Students in English-Speaking Countries. International Education Studies, 11(6), 22-44. https://doi.org/10.5539/ies.v11n6p22

Almomani, E. Y., Qablan, A. M., Almomany, A. M., \& Atrooz, F. Y. (2021). The coping strategies followed by university students to mitigate the COVID-19 quarantine psychological impact. Current Psychology, 1-10. https://doi.org/10.1007/s12144-021-01833-1

Brunsting, N. C., Zachry, C., \& Takeuchi, R. (2018). Predictors of undergraduate international student psychosocial adjustment to US universities: A systematic review from 2009-2018. International Journal of Intercultural Relations, 66, 22-33. https://doi. org/10.1016/j.ijintrel.2018.06.002

Chen, D., \& Yang, X. (2014). Striving and Thriving in a Foreign Culture: A Mixed Method Approach on Adult International Students' Experience in U.S.A. Journal of Education and Training Studies. 2(3), 16-25. https://doi.org/10.11114/jets.v2i3.353

Chen, J. H., Li, Y., Wu, A. M. S., \& Tong, K. K. (2020). The overlooked minority: Mental health of International students worldwide under the COVID-19 pandemic and beyond. Asian Journal of Psychiatry, 54, 102333. https://doi.org/10.1016/j.ajp.2020. 102333

Chirikov, I., \& Soria, K. M. (2020). International students' experiences and concerns during the pandemic. University of California - Berkeley and University of Minnesota.

Chirikov, I., Soria, K. M., Horgos, B., \& Jones-White, D. (2020). Undergraduate and Graduate Students' Mental Health During the COVID-19 Pandemic. SERU Consortium Reports. https://escho larship.org/uc/item/80k5d5hw

Eichstaedt, J. C., Sherman, G. T., Giorgi, S., Roberts, S. O., Reynolds, M. E., Ungar, L. H., \& Guntuku, S. C. (2021). The emotional and mental health impact of the murder of George Floyd on the US population. Proceedings of the National Academy of Sciences, 118(39), e2109139118. https://doi.org/10.1073/pnas.2109139118

Essau, C. A., \& Trommsdorff, G. (2016). Coping with UniversityRelated Problems: A Cross-Cultural Comparison. Journal of Cross-Cultural Psychology. 27(3), 315-328. https://doi.org/10. 
1177/0022022196273004,27(3),315-328.10.1177/0022022196 273004

Franz, B., Milner, A., \& Braddock, I. I. J. H. (2021). Do Black Lives Matter in the American Public's Mitigation Responses to the COVID-19 Pandemic? An Analysis of Mask Wearing and Racial/ Ethnic Disparities in Deaths from COVID-19. Journal of Racial and Ethnic Health Disparities. 1-7. https://doi.org/10.1007/ s40615-021-01097-2

Fritz, M. V., Chin, D., \& DeMarinis, V. (2008). Stressors, anxiety, acculturation and adjustment among international and North American students. International Journal of Intercultural Relations, 32(3), 244-259.

Glaser, B. G., \& Strauss, A. L. (2017). Discovery of grounded theory: Strategies for qualitative research. Routledge. https://doi.org/10. 4324/9780203793206

Glass, C. R., \& Westmont, C. M. (2014). Comparative effects of belongingness on the academic success and cross-cultural interactions of domestic and international students. International Journal of Intercultural Relations, 38(1), 106-119. https://doi. org/10.1016/J.IJINTREL.2013.04.004

Gupta, R., \& Agrawal, R. (2021). Are the concerns destroying mental health of college students?: A qualitative analysis portraying experiences amidst COVID-19 ambiguities. Analyses of Social Issues and Public Policy. https://doi.org/10.1111/asap.12232

Heng, T. T. (2017). Voices of Chinese international students in USA colleges: 'I want to tell them that ....'. Studies in Higher Education. 42(5), 833-850. https://doi.org/10.1080/03075079.2017. 1293873

Heng, T. T. (2018). Different is not deficient: Contradicting stereotypes of Chinese international students in US higher education. Studies in Higher Education. 43(1), 22-36. https://doi.org/10. 1080/03075079.2016.1152466

Higher Education Fourth Supplemental Letter. American Council on Education. (2020).

Ho, J. (2021). Anti-Asian racism, Black Lives Matter, and COVID19. Japan Forum, 33(1), 148-159. https://doi.org/10.1080/ 09555803.2020 .1821749

Hu, S., Cai, D., Zhang, X. C., \& Margraf, J. (2020). Relationship between social support and positive mental health: A three-wave longitudinal study on college students. Current Psychology, 1-10. https://doi.org/10.1007/s12144-020-01175-4.

Immigration, Refugees and Citizenship Canada (2021). Government of Canada announces further measures to support international students. https://www.canada.ca/en/immigration-refugees-citiz enship/news/2021/02/government-of-canada-announces-furth er-measures-to-support-international-students.html?_cldee $=$ bGFycnkucm9zaWFAc2Fza3BvbH10ZWNoLmNh\&recipientid=contact-ff33a667f 1 ade $711810 f c 4346$ bac2a20- Accessed date 14 Aug 2021

International Student Services - Columbus State University (2021). International Student Friendship Program. Accessed date 14 Aug 2021 https://international.columbusstate.edu/services/frien dship-program.php

International Student Services - University of Wisconsin-Madison (2020). Invitation to an Open forum on Current Events \& the Racial Tensions within the U.S. Accessed date 14 Aug 2021 https://iss.wisc.edu/invitation-to-an-open-forum-on-curre nt-events-the-racial-tensions-within-the-u-s/

Jayasekara, R. S. (2012). Focus groups in nursing research: Methodological perspectives. Nursing Outlook, 60(6), 411-416. https:// doi.org/10.1016/j.outlook.2012.02.001

Kwenani, D. (Farwick), \& Yu, X. (2018). Maximizing International Students' Service-Learning and Community Engagement
Experience: A Case Study of Student Voices on the Benefits and Barriers. Journal of Higher Education Outreach and Engagement, 22(4), 29-52. Accessed date 14 Aug 2021 https://openj ournals.libs.uga.edu/jheoe/article/view/1416

Laws, K., \& Ammigan, R. (2020). International Students in the Trump Era: A Narrative View. Journal of International Students. 10(3), xviii-xxii https://doi.org/10.32674/jis.v10i3.2001

Marbang, P., Mckinzie, A. E., Eller, J., \& Leggett, I. F. (2020). International Students' Experiences with Changing Policy: A Qualitative Study from Middle Tennessee. Journal of Interdisciplinary Studies in Education. 9(2), 311-337. http://ojed.org/jise

Mchugh, M. L. (2012). Interrater reliability: the kappa statistic Importance of measuring interrater reliability. Biochemia Medica (Zagreb). 22(3):276-82.

Meiksin, J. (2020). US visa problems amid COVID-19 disrupt materials research. MRS Bulletin. 45(8), 616-617. https://doi.org/10. 1557/mrs.2020.208

Morgan, D. L. (1996). Focus groups. Annual Review of Sociology, 22(1), 129-152. https://doi.org/10.1146/annurev.soc.22.1.129

Ngoc Cindy Pham, \& Juehui Richard Shi. (2020). A qualitative study on mental distress of Vietnamese students in the U.S.A. in the COVID 19 era I Asia Pacific Journal of Health Management. Asia Pacific Journal of Health Management, 15(3), 45-57. https://doi. org/10.3316/informit.308860150202375

Pappa, S., Yada, T., \& Perälä-Littunen, S. (2020). International Master's Degree Students' Well-being at a Finnish University During COVID-19. Open Education Studies, 2(1), 240-251. https://doi. org/10.1515/EDU-2020-0128

Poyrazli, S., \& Lopez, M. D. (2007). An exploratory study of perceived discrimination and homesickness: A comparison of international students and American students. The Journal of Psychology. 141(3), 263-280. https://doi.org/10.3200/JRLP.141.3.263-280

Redden, E. (2020). New International Students Barred From All-Online Classes. Inside Higher ED.

Redfern, K. (2016). An empirical investigation of the incidence of negative psychological symptoms among Chinese international students at an Australian university. Australian Journal of Psychology, 68(4), 281-289.

Saravanan, C., \& Subhashini, G. (2021). A Systematic Review on the Prevalence of Depression and its Associated Factors among International University Students. Current Psychiatry Research and Reviews Formerly: Current Psychiatry Reviews, 17(1), 13-25.

Shadowen, N. L., Williamson, A. A., Guerra, N. G., Ammigan, R., \& Drexler, M. L. (2019). Prevalence and correlates of depressive symptoms among international students: Implications for university support offices. Journal of International Students, 9(1), 129-148. https://doi.org/10.32674/jis.v9i1.277

Smith, R. A., \& Khawaja, N. G. (2011). A review of the acculturation experiences of international students. International Journal of Intercultural Relations. 35(6), 699-713. https://doi.org/10.1016/j. ijintrel.2011.08.004

Taliaferro, L. A., Muehlenkamp, J. J., \& Jeevanba, S. B. (2018). Factors Associated with Emotional Distress and Suicidality among International College Students. Journal of Adolescent Health, 62(2), S8-S9. https://doi.org/10.1016/j.jadohealth.2017.11.019

Thi Tran, L. (2020). Teaching and Engaging International Students: People-to-People Connections and People-to-People Empathy. Journal of International Students, 10(3), 2166-3750. https://doi. org/10.32674/jis.v10i3.2005

Tong, A., Sainsbury, P., \& Craig, J. (2007). Consolidated criteria for reporting qualitative research (COREQ): A 32-item checklist for interviews and focus groups. International Journal for Quality 
in Health Care, 19(6), 349-357. https://doi.org/10.1093/intqhe/ mzm042

Toure, K., Langlois, E. V., Shah, M., McDougall, L., \& Fogstad, H. (2021). How George Floyd and COVID-19 are highlighting structural inequities for vulnerable women, children and adolescents. International Journal for Equity in Health, 20(1), 193. https://doi. org/10.1186/s12939-021-01540-0

Trout, I. Y., \& Alsandor, D. J. (2020). Graduate student well-being: Learning and living in the U.S. during the COVID-19 pandemic. International Journal of Multidisciplinary Perspectives in Higher Education, 5(1), 150-155. https://doi.org/10.32674/JIMPHE. V5I1.2576

Wang, Z.-H., Yang, H.-L., Yang, Y.-Q., Liu, D., Li, Z.-H., Zhang, X.-R., Zhang, Y.-J., Shen, D., Chen, P.-L., Song, W.-Q., Wang, X.-M., Wu, X.-B., Yang, X.-F., \& Mao, C. (2020). Prevalence of anxiety and depression symptom, and the demands for psychological knowledge and interventions in college students during COVID-19 epidemic: A large cross-sectional study. Journal of Affective Disorders, 275, 188-193. https://doi.org/10.1016/j.jad. 2020.06 .034
Xiaomei, Hegde, S., Son, C., Keller, B., Smith, A., \& Sasangohar, F. (2020). Investigating Mental Health of US College Students During the COVID-19 Pandemic: Cross-Sectional Survey Study. J Med Internet Res. 22(9), e22817. https://doi.org/10.2196/22817

Zhai, Y., Zhang, L., Yan, Z., \& Wei, Y. (2021). Social dominance orientation, social contact, and attitudes toward international students. Current Psychology, 1-11. https://doi.org/10.1007/ s12144-020-01311-0

Zheng, Y., Goh, E., \& Wen, J. (2020). The effects of misleading media reports about COVID-19 on Chinese tourists' mental health: a perspective article. Anatolia. 31(2), 337-340. https://doi.org/10. 1080/13032917.2020.1747208

Publisher's Note Springer Nature remains neutral with regard to jurisdictional claims in published maps and institutional affiliations. 